\title{
Gangliogliomas: clinical, radiological, and histopathological findings in 51 patients
}

\author{
Josef Zentner, Helmut K Wolf, Burkhard Ostertun, Andreas Hufnagel, \\ Manuel G Campos, Laszlo Solymosi, Johannes Schramm
}

\begin{abstract}
Clinical, radiological, and histopathological features of 51 surgically treated gangliogliomas were evaluated retrospectively. The most common presenting symptoms were epileptic seizures $(47$ patients (92\%)). Focal neurological deficits occurred in $8 \%$ of the patients. The duration of symptoms at the time of operation ranged from three months to 45 years, mean 11 years. The temporal lobe was affected in 43 patients $(84 \%)$, the frontal lobe in five patients $(10 \%)$, and the occipital lobe in one patient $(2 \%)$. Two of the tumours (4\%) were localised infratentorially. On MRI, solid tumour parts usually showed a pronounced signal increase on proton density images and a less pronounced signal increase on $T 2$ weighted images, whereas solid components were mainly isointense on $\mathrm{T} 1$ weighted images. Contrast enhancement was noted in 16 of 36 patients (44\%). Cystic tumour parts were found in 23 of 40 patients $(57 \%)$, all characterised by signal increase on $\mathrm{T} 2$ weighted images and decreased $T 1$ signals. Signal deviation of cystic tumour parts on proton density images was variable. Computed tomography was performed in 17 patients and showed hypodense lesions in $10(59 \%)$, and calcifications in seven (41\%) cases. Surgery included complete tumour removal in 44 patients $(86 \%)$ and partial resection in seven $(14 \%)$. In six patients $(12 \%)$ there were transient postoperative complications. One patient (2\%) died postoperatively due to pulmonary embolism. Histopathological examination of the surgical specimens showed low grade gangliogliomas in 49 cases $(96 \%)$ and anaplastic gangliogliomas in two (4\%). Control MRI of 31 patients with a mean follow up period of 16 months was uneventful in all but one case of an anaplastic ganglioglioma. In all patients in whom the ganglioglioma was associated with medically intractable seizures the operation resulted in complete relief of seizures or a noticeable improvement of the epilepsy.
\end{abstract}

$(\mathcal{F}$ Neurol Neurosurg Psychiatry 1994;57:1497-1502) of Neurosurgery, SigmundFreud-Straße 25 ,

53105 Bonn, Germany.

Received 21 March 1994

Accepted for publication

27 May 1994
Keywords: Ganglioglioma; magnetic resonance imaging; computerised tomography; temporal lobe epilepsy.
Gangliogliomas are rather infrequent lesions of the CNS and account for 0.4 to $1.3 \%$ of all brain tumours, with a higher incidence in infancy. ${ }^{1-6}$ The term ganglioglioma was introduced by Perkins in $1926 .{ }^{7}$ In 1930 , Courville provided a review of the literature on 20 gangliogliomas. ${ }^{8}$ Since then there has been only a single abstracted report on the clinical and radiological features of these lesions that deals with a large number of patients. ${ }^{9}$ Other reported series have been limited to small case numbers. ${ }^{13510-15}$ During the past five years, we have operated on 51 patients with gangliogliomas, most of whom had chronic pharmacoresistant epilepsy. Here we present a comprehensive review of the clinical, radiological, and histopathological findings in these patients.

\section{Patients and methods}

This study includes 51 patients with gangliogliomas who were treated surgically during a five year period (January 1988-February 1993) at the Department of Neurosurgery, University of Bonn. During this period, a total of 1325 brain tumours, including 978 intrinsic brain tumours, were operated on. Thus gangliogliomas accounted for $3.8 \%$ of all brain tumours and for $5 \cdot 2 \%$ of intrinsic brain tumours at our institution. All patients with medically intractable epilepsy underwent extensive presurgical evaluation, to clearly define the epileptogenic area. This included non-invasive or invasive electroencephalographic studies as well as neuropsychological and psychiatric testing.

The clinical charts of all patients were reviewed with regard to the presenting signs and symptoms, duration of symptoms until diagnosis, diagnostic and therapeutic modalities, and the postoperative outcome. Follow up clinical information was available for 40 patients and MRI for 31, with follow up periods ranging from three months to four years (mean 16 months). Due to the fact that many of our patients were referred to this medical centre from distant cities we were unable to obtain follow up information in all of our patients.

Preoperative CT was available from 17 patients. Fourteen of these had been examined with and without contrast enhancement. Magnetic resonance imaging was available from 40 patients. Complete MRI studies comprising $\mathrm{T} 1$ weighted images with and without gadolinium, proton density, and T2 weighted images had been obtained from 36 
Table 1 Signs and symptoms in 51 patients with gangliogliomas

\begin{tabular}{lll}
\hline & \multicolumn{2}{l}{ Patients } \\
\cline { 2 - 3 } Sign/symptom & No & $(\%)$ \\
\hline Epilepsy & 47 & $(92)$ \\
Cranial nerve deficit & 1 & $(2)$ \\
Hemiparesis & 1 & $(2)$ \\
Tetraparesis & 2 & $(4)$ \\
Increased ICP & 2 & $(4)$ \\
\hline
\end{tabular}

ICP $=$ intracranial pressure

Table 2 CT findings in 17 gangliogliomas. Frequency of hypodense (cystic), enhancing and calcified tumour components is shown. In one case, the tumour was not visible on contrast enhanced $C T$

\begin{tabular}{|c|c|c|c|c|}
\hline & \multicolumn{3}{|l|}{$C T$ pattern } & \multirow{2}{*}{$\begin{array}{l}\text { Patient } \\
\text { No }\end{array}$} \\
\hline & Hypodense & Enhancing & $\overline{\text { Calcified }}$ & \\
\hline & + & - & - & 6 \\
\hline & - & - & + & 4 \\
\hline & + & + & + & 2 \\
\hline & - & + & - & 2 \\
\hline & + & + & - & 1 \\
\hline & + & - & + & 1 \\
\hline & - & - & - & 1 \\
\hline No & 10 & 5 & 7 & 17 \\
\hline
\end{tabular}

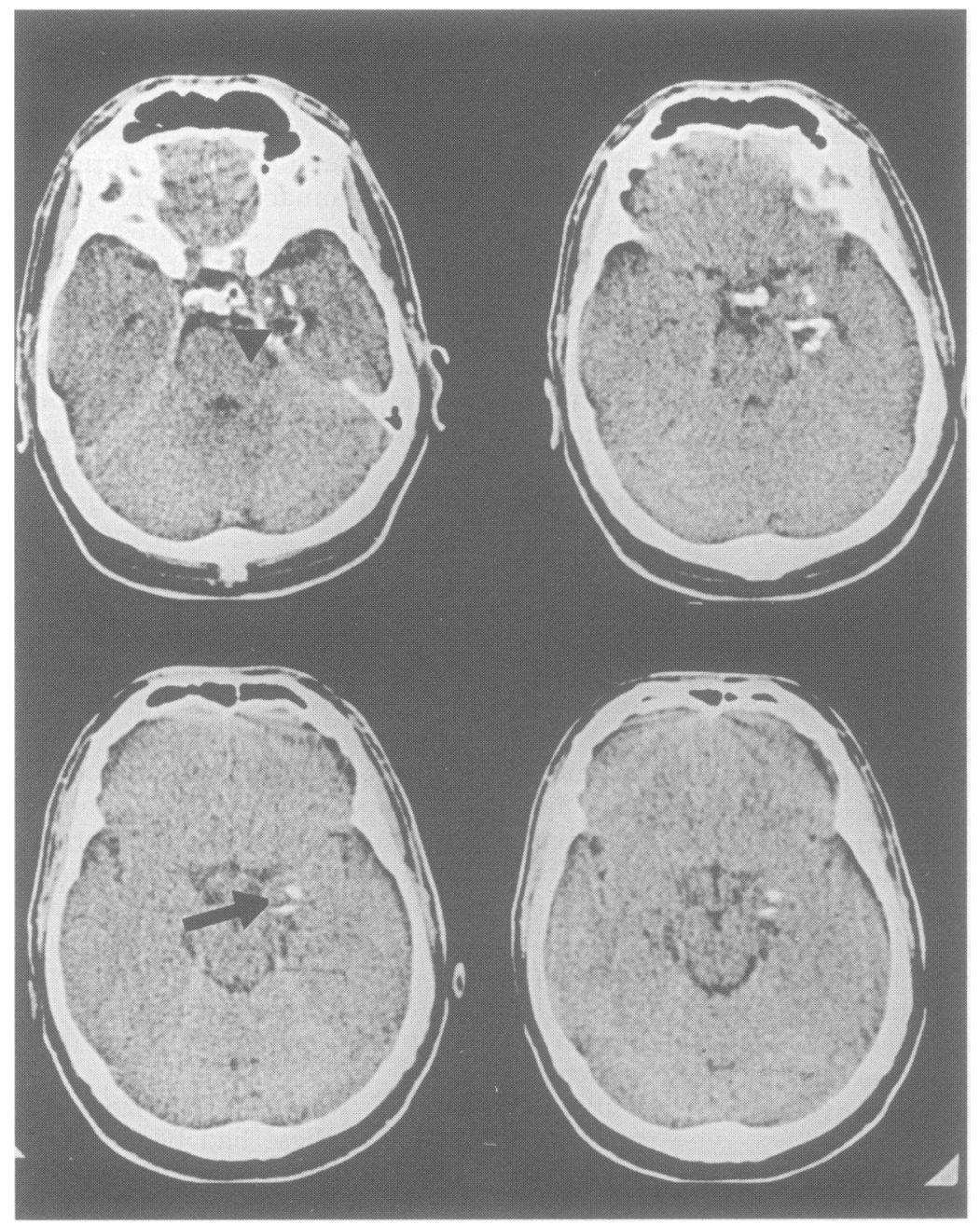

Figure 1 Non-enhanced CT of a 36 year old patient with a ganglioglioma (WHO grade I) of the left hippocampus. In between calcifications there is a hypodense solid tumour component (arrow). The slice shows a cystic tumour part that is isodense with CSF (arrow head). cases. All CT and MRI scans were reviewed by a neuroradiologist.

Histological preparations of specimens from operation were reviewed by two neuropathologists. In all cases the following stains and immunohistopathological reactions were used: haematoxylin-eosin, Nissl, glial fibrillary acid protein (GFAP), synaptophysin, neurofilament protein (NFP), and neuron specific enolase (NSE). The tumours were classified according to the revised World Health Organisation (WHO) classification for tumours of the nervous system. ${ }^{16}$

\section{Results}

CLINICAL FINDINGS

There were 29 male and 22 female patients. Ages ranged from 2 to 50 (mean 25) years. Forty seven patients $(92 \%)$ presented with an epileptic seizure disorder that was pharmacoresistant in 40 cases $(78 \%)$. The predominant seizure pattern was that of complex partial seizures. In three of the epileptic patients, the psychomotor development was noticeably retarded. Focal neurological deficits were found in four cases $(8 \%)$. Two patients $(4 \%)$ presented with signs of increased intracranial pressure (table 1). At the time of operation the duration of symptoms ranged from three months to 45 (mean 11) years. In patients treated for epilepsy, the mean duration of symptoms was 13 years as opposed to three years in patients operated on without chronic pharmacoresistant seizure disorders.

\section{NEURORADIOLOGICAL FINDINGS}

The tumours were located in the temporal lobe in 43 cases $(84 \%)$, in the frontal lobe in five cases $(10 \%)$, in the occipital lobe in one case $(2 \%)$, and infratentorially with involvement of the pons and medulla oblongata in two cases ( $4 \%$ ).

Native CT showed a hypodense lesion in 10 of 17 patients (59\%). Calcifications were detected in seven cases ( $41 \%$; fig 1 ). Lesion enhancement was present in five of $14(36 \%)$ scans performed with contrast. The pattern of enhancement was inhomogeneous in two and homogeneous in three cases. The tumour was invisible on native CT in two cases $(12 \%)$ and on contrast enhanced CT in one case $(7 \%)$ (table 2).

Gangliogliomas appeared on $\mathrm{MRI}$ as entirely solid ( $n=17 ; 43 \%)$, completely cystic ( $n=2 ; 5 \%)$, or lesions with both solid and cystic parts $(n=21 ; 52 \%)$. Solid tumour parts were identified in 38 of 40 patients (95\%). Only 36 patients were, however, examined with gadolinium. Of these, 10 contained one homogeneously enhancing solid component only (fig 2 ). The remaining six tumours were each composed of two different solid areas one of which was enhancing and the other non-enhancing. We evaluated the signal behaviour of these solid components separately so that a total of 44 solid tumour areas ( 38 plus six) were studied (table 3). The characteristic signal pattern of these 44 solid parts was a moderate or pronounced 
Figure 2 MRI of an 18 year old male patient with a ganglioglioma (WHO grade I) of the left supramarginal gyrus. T2 weighted axial (left) and contrast enhanced T1 weighted coronal images (right) are shown. The tumour enhances

homogeneously. There is no evidence of cystic parts.

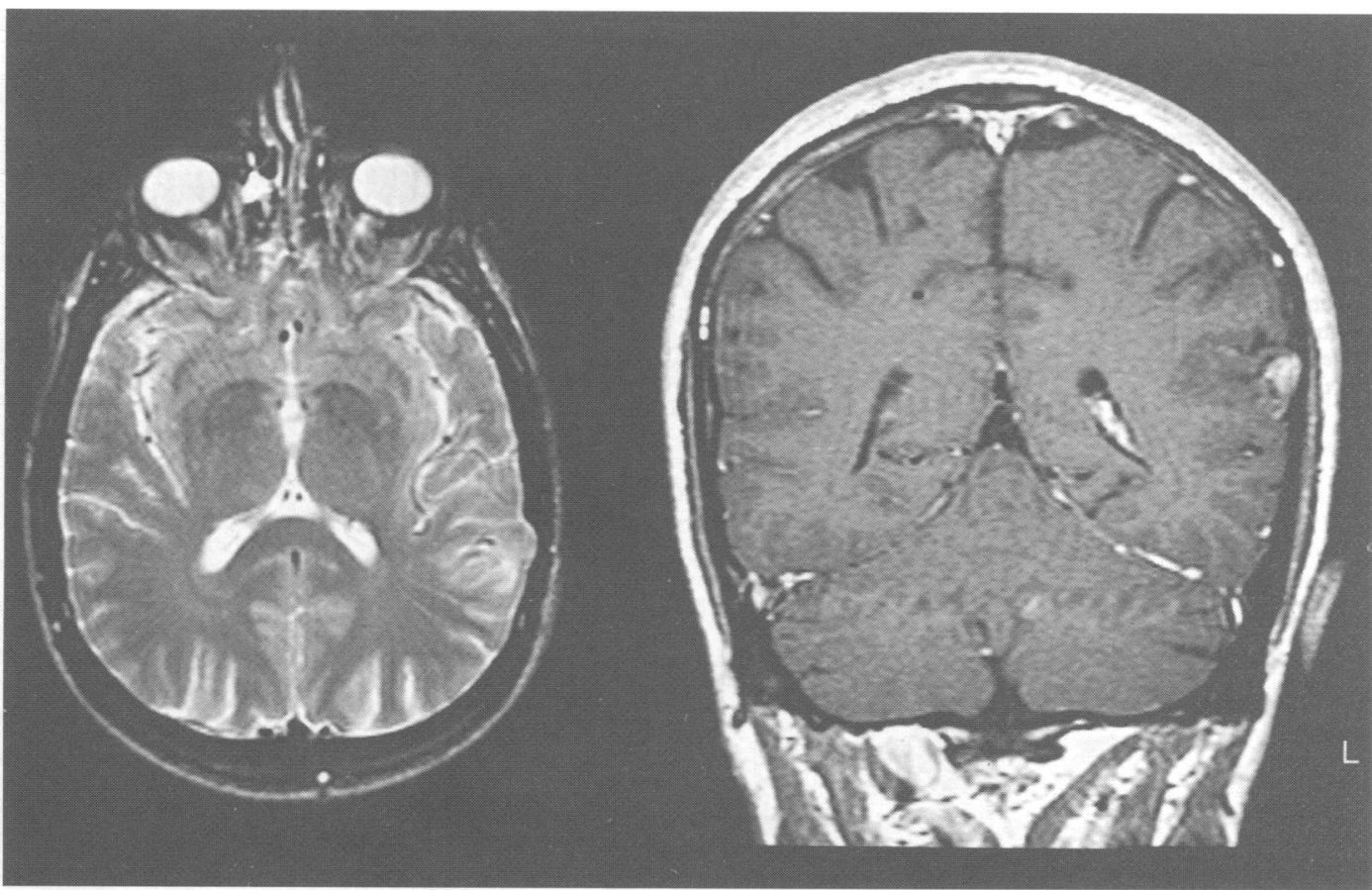

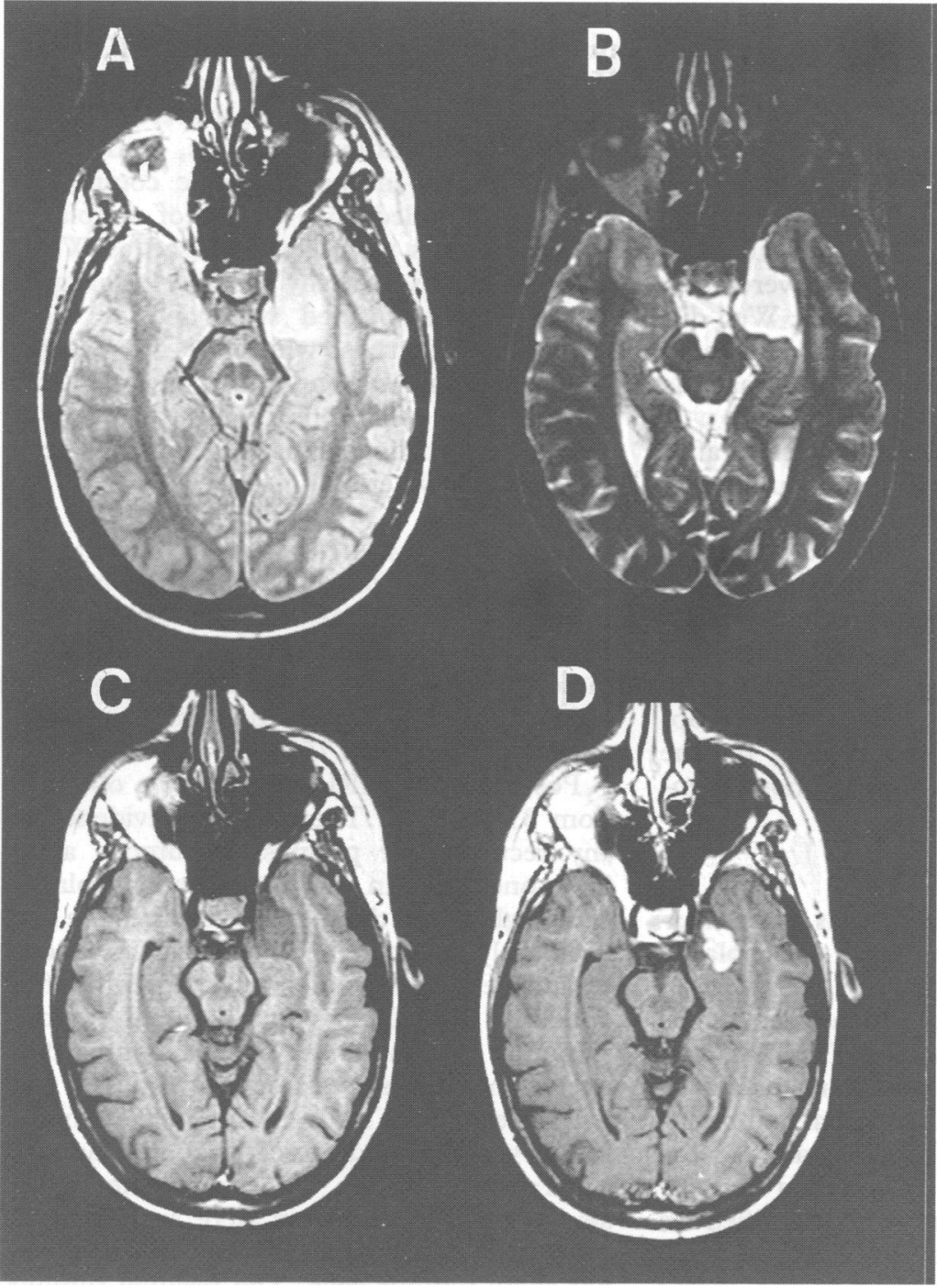

Figure 3 MRI of a 21 year old patient with a ganglioglioma (WHO grade I) of the left uncus. Proton density weighted image $(A)$ and $T 2$ weighted image $(B)$ show a homogeneous signal increase. $T 1$ weighted image $(C)$ shows decreased signal. Contrast enhanced T1 weighted image (D) shows an inhomogeneous signal increase of the solid tumour part, whereas the mesially localised cystic component does not enhance. hyperintensity on proton density weighted images, whereas on T2 weighted images 14 of the $44(32 \%)$ solid parts were isointense or even hypointense. On T1 weighted nonenhanced images, solid components were typically isointense. Cystic tumour components were found in 23 patients $(57 \%)$. They were characterised by hypointensity on $\mathrm{T} 1$, strong hyperintensity on $\mathrm{T} 2$, and variable signal deviations on proton density weighted images (table 3; fig 3).

SURGICAL TREATMENT AND COMPLICATIONS Surgical treatment included complete tumour removal in 44 patients $(86 \%)$ and partial resection in seven (14\%). Of the 34 patients with temporal lobe gangliogliomas treated for medically intractable epilepsy, anterior temporal lobectomy including hippocampectomy was performed in 31 cases, and extended lesionectomy without hippocampectomy in three cases. In all six patients with gangliogliomas of the frontal or occipital lobe extended lesionectomy was performed

\section{Table 3 MRI findings in 40 gangliogliomas}

\begin{tabular}{|c|c|c|c|c|c|c|c|c|}
\hline \multirow[b]{2}{*}{$\begin{array}{l}\text { Tumour } \\
\text { component }\end{array}$} & \multirow[b]{2}{*}{$\begin{array}{l}\text { Spin echo } \\
\text { sequence }\end{array}$} & \multicolumn{4}{|c|}{ Signal deviation } & \multicolumn{3}{|c|}{ Enhancement } \\
\hline & & No $\stackrel{\downarrow}{\text { No }}$ & $\overrightarrow{N o}$ & $\uparrow_{\text {No }}$ & $\stackrel{\vec{N}}{N o}$ & No & $\stackrel{\bigcirc}{\text { No }}$ & $\stackrel{\bigcirc}{N o}$ \\
\hline $\begin{array}{l}\text { Solid } \\
n=44\end{array}$ & $\begin{array}{l}\text { T1 } \\
\text { PD } \\
\text { T2 }\end{array}$ & $\begin{array}{ll}- & 9 \\
- & 1 \\
- & 1\end{array}$ & $\begin{array}{l}32 \\
- \\
13\end{array}$ & $\begin{array}{r}1 \\
26 \\
21\end{array}$ & $\begin{array}{r}2 \\
17 \\
9\end{array}$ & 5 & 4 & 7 \\
\hline $\begin{array}{l}\text { Cystic } \\
n=23\end{array}$ & $\begin{array}{l}\text { T1 } \\
\text { PD } \\
\text { T2 }\end{array}$ & $\begin{array}{rr}13 & 10 \\
2 & 8 \\
- & -\end{array}$ & $\begin{array}{l}- \\
-\end{array}$ & $\begin{array}{r}- \\
7 \\
2\end{array}$ & $\begin{array}{r}- \\
21\end{array}$ & - & - & - \\
\hline
\end{tabular}

The solid tumour components were divided into enhancing and non-enhancing parts. Thus $\mathbf{4 4}$ solid tumour components were evaluated. Contrast enhancement was seen in 16 of 44 solid tumour components, whereas 28 did not enhance. $\mathrm{PD}=$ proton density.

Arrows reflect increased $(\uparrow)$ or decreased $(\downarrow)$ signal. Circle diameters reflect degree of enhancement. 
Figure 4 Photomicrograph of a ganglioglioma (WHO gange I). The lesion consists of a mixture of disfigured ganglion cells and astrocytes. The ganglion cells are ganglion cells are
characterised by prominent nucleoli and Nissl substance and lack of $a$ uniform orientation (haematoxylin-eosin originally $\times 240$ ).

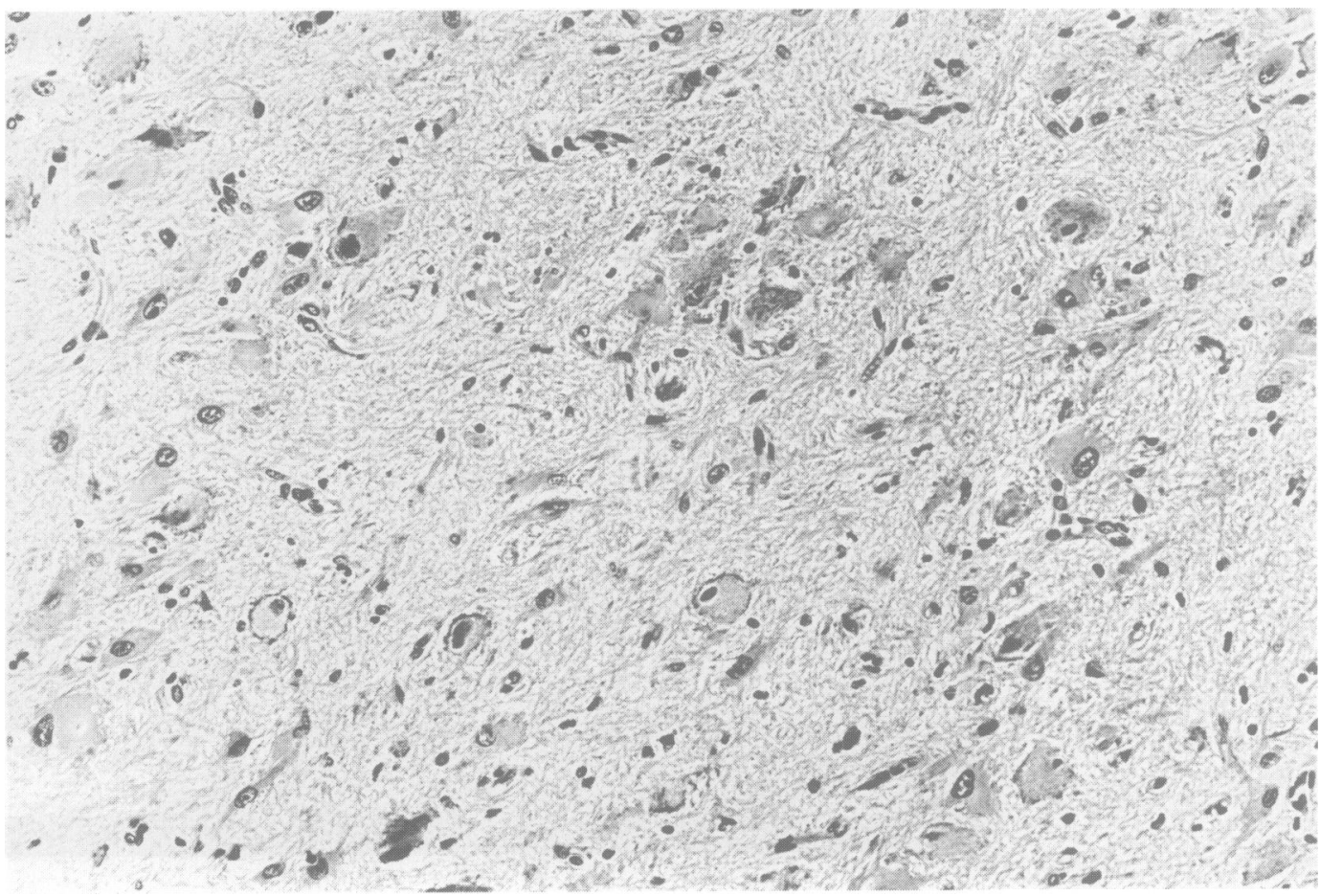

according to the results of presurgical epileptological evaluation.

Intraoperatively, solid and cystic tumour components were easily recognised. The solid tumour parts were usually of a yellowish or brownish colour, often of firm consistency, and they were well demarcated from adjacent gyri and sulci. Cystic tumour parts were often seen between the solid components. Well differentiated tumours could be easily separated from surrounding structures such as the Sylvian fissure and the brain stem.

One patient $(2 \%)$ died two weeks after operation due to massive pulmonary embolism. Transient morbidity was encountered in six patients (12\%). These complications included third nerve paresis in two cases, wound infection requiring removal of the bone flap in one case, and deep vein thrombosis in another case. Two patients had mild temporary peripheral nerve deficits probably due to inadequate positioning on the operation table. All these complications eventually resolved completely.

HISTOPATHOLOGICAL FINDINGS

Histologically, the gangliogliomas were characterised by an intimate mixture of neoplastic astrocytes and atypical ganglion cells (fig 4). Nissl stains and immunohistochemical stains for neuronal (synaptophysin, NFP, NSE) and astrocytic (GFAP) markers were useful in highlighting the neuronal and glial cell populations and provided a valuable aid for the diagnosis of small and fragmented tumour samples. Ganglion cells were identified as such by the demonstration of Nissl substance and large nucleoli. According to the WHO classification, we found WHO grade I tumours in 44 patients $(86 \%)$. Based on a high cellularity and cellular and nuclear pleomorphism of the glial component, five tumours $(10 \%)$ were classified as WHO grade II lesions. Two gangliogliomas (4\%) contained areas of pronounced hypercellularity, vascular proliferation, necrosis, and many mitotic figures in the astrocytic component and thus fulfilled the criteria of anaplasia. These tumours were characterised as WHO grade III lesions. In many patients, the ganglioglioma was associated with one or more glioneural hamartias, which are microscopic malformed lesions composed of glial elements and ganglion cells. One of the two cases of anaplastic gangliogliomas has recently been described elsewhere. ${ }^{17}$

\section{FOLLOW UP EXAMINATION}

Clinical data on follow up examinations were available in 40 patients, all of whom had presented with pharmacoresistant epilepsy. Of these, 32 patients $(80 \%)$ were seizure free and eight $(20 \%)$ had a reduction in seizure frequency of more than $75 \%$.

Postoperative MRI controls were obtained from 31 patients. There was no evidence of any recurrent or progressive tumour apart from one case. In this patient an anaplastic ganglioglioma of the mesial temporal lobe had been only incompletely removed. Magnetic resonance imaging performed six months after operation showed a small residual tumour along the Sylvian fissure. Twelve months after operation, MRI showed several zones of signal increases on T2 weighted images in the fourth ventricle and the cervical and thoracic subarachnoid space. Thus drop metastases along the CSF pathways were suspected. A cytological examination of CSF, however, did not show tumour cells. The residual tumour along the Sylvian fissure was unchanged with no clear evidence of tumour progression. Neurological examination at this time showed no abnormalities. The other patient with an 
anaplastic ganglioglioma died shortly after operation due to pulmonary embolism.

\section{Discussion}

Gangliogliomas are tumours of the CNS that are composed of atypical ganglion cells and astrocytes. Zülch ${ }^{6}$ found gangliogliomas in $0.4 \%$ and Cushing ${ }^{18}$ in $0.3 \%$ of a comprehensive series of brain tumours. According to recent studies, gangliogliomas account for 0.4 to $7.6 \%$ of paediatric CNS neoplasms ${ }^{235}$ and up to $1 \cdot 3 \%$ of those in adults. ${ }^{4}$ The high ratio of gangliogliomas among intrinsic brain tumours at our institution $(5 \cdot 2 \%)$ reflects the high incidence of this tumour in patients with epilepsy. ${ }^{19-21}$ The temporal lobe is the most common location of gangliogliomas. ${ }^{3562223}$ Also, gangliogliomas may be found at virtually any location of the CNS such as the spinal cord, ${ }^{24-27}$ brain stem, ${ }^{28}{ }^{29}$ third and fourth ventricle, ${ }^{30}$ cerebellum, ${ }^{1331}$ pineal region, ${ }^{32}{ }^{33}$ thalamus, ${ }^{5}$ and optic nerve. ${ }^{34} 35$

Most patients present with long histories of seizures, whereas focal neurological deficits or increased intracranial pressure are unusual. In our series, epilepsy was found in 47 of 51 patients (92\%). This is in agreement with previous reports in which seizures were the presenting symptom in 62 to $100 \%$ of patients with hemispheric tumours. ${ }^{145111336}$ Focal neurological deficits, as present in four of our patients $(8 \%)$, have mainly been found in patients with parietal tumours or tumours in locations such as the thalamus, brain stem, or spinal cord. ${ }^{13}$ The age at presentation ranged between 2 and 50 (mean 25) years in our series, which is similar to other reports. ${ }^{45913}$ There was no sex preponderance in any of the reported series, including our own.

Our CT findings are similar to other series. The tumours were hypodense in $59 \%$. Calcifications were present in $41 \%$ and there was contrast enhancement in $36 \%$. Hypodense lesions on CT were reported in the literature in 40 to $100 \%$, calcifications in 20 to $50 \%$, and contrast enhancement in 16 to $80 \%$ of gangliogliomas. ${ }^{145101136}$ The fact that the tumour was invisible on native CT in two of our patients and on contrast enhanced CT in one case highlights the importance of MRI for the diagnosis of gangliogliomas.

Magnetic resonance imaging has proved to be more sensitive in identifying gangliogliomas than CT. In agreement with previous reports, ${ }^{1011} 57 \%$ of the tumours had cystic components, which were hypointense on $\mathrm{T} 1$ weighted images and hyperintense on T2 weighted images. Forty three per cent of the tumours appeared only as solid lesions with typically pronounced signal increase on proton density weighted images and less pronounced hyperintensity on T2 weighted images. Most remarkably, there was usually isointensity on T1 weighted images. The pattern of contrast enhancement in MRI studies of gangliogliomas has not been reported in detail in previous studies. Gadolinium enhancement was present in 16 of 36 patients $(44 \%)$ in our series. Magnetic resonance imaging was performed in eight patients in the series of Haddad et al with contrast enhancement in one patient (12\%). ${ }^{11}$ Hypointense lesions on $\mathrm{T} 1$ and hyperintense lesions on T2 weighted images were also found in two spinal gangliogliomas. ${ }^{37}$ Tumour cysts may show a higher signal than CSF on T2 weighted images. Irregular margins and associated soft tissue components help to distinguish the tumour cysts from simple cysts. This corresponds with the intraoperative finding that cystic tumour parts may consist of a gelatinous mass. ${ }^{37}$ Moreover, MRI is a valuable aid in defining the exact location and border of a tumour in different planes, which is indispensable for the planning of complete tumour removal. Tampieri et al, ${ }^{20}$ however, found two patients with gangliogliomas, in whom MRI was normal. In our series there was a single case in which the ganglioglioma was not detected by MRI, probably due to the technical limitations of a first generation MRI scanner.

The extent of resection is thought to be the main prognostic factor in the treatment of gangliogliomas. ${ }^{1311}$ The present results with a complete seizure relief in $80 \%$ and a significant improvement $(>75 \%$ reduction in seizure frequency) in the remaining $20 \%$ of the patients compare favourably with most previous reports on smaller series in which relief of seizures after operation was found in $50-90 \%$ of the patients. ${ }^{5} 91115$ In accordance with Haddad et $a{ }^{11}$ all patients with total resection were tumour free at the last follow up.

For most gangliogliomas, radiation therapy seems to be of no benefit. ${ }^{513}$ None of our patients received postoperative irradiation treatment. Garrido $e t a l^{3}$ found no difference in outcome with or without radiation therapy in four cases. Most authors recommend that radiation therapy should be reserved only for those patients with tumour progression. ${ }^{13513}$ Whether anaplastic gangliogliomas will benefit from radiation therapy or chemotherapy has not been studied. In one case of anaplastic ganglioglioma in our series, MRI indicated spinal drop metastases 12 months after surgery, which suggests that postoperative radiation therapy might be useful in anaplastic gangliogliomas (WHO grade III). Similarly, the relevance of increased cellularity and cellular and nuclear pleomorphism without frank anaplasia (WHO grade II lesions) remains uncertain at the present time and is awaiting long term follow up.

The origin of gangliogliomas remains obscure. Some findings support the hypothesis that gangliogliomas represent developmental lesions. These include histopathological evidence of disordered neuronal migration and a long clinical history in many patients. A single case of a congenital ganglioglioma of the occipital lobe presenting with quadrantic anopsia has been reported. ${ }^{38}$

In conclusion, gangliogliomas are usually benign tumours composed of neuronal and glial elements. The temporal lobes are the preferred site. Clinically, gangliogliomas are 
typically associated with chronic pharmacoresistant epileptic seizure disorders in children or younger adults. Neuroradiologically, there is no single pathognomonic finding. In the appropriate clinical setting, a ganglioglioma should be strongly considered in the presence of a tumour like lesion with both solid and cystic components on MRI. The presence of calcifications, which are more readily detected by CT than MRI, provides further support for the tentative diagnosis of a ganglioglioma. Complete tumour removal seems to be the treatment of choice. In patients with medically intractable epilepsy, surrounding brain areas that are considered to be epileptogenic as determined by extensive presurgical evaluation should also be excised. Although most gangliogliomas appear histopathologically benign and run a clinically benign course, long term follow up of additional cases is necessary for a clear definition of the biological behaviour of these lesions.

This paper was presented in part at the annual meeting of the German Society of Neurosurgeons, Marburg, Germany, 2-5 May 1993.

1 Demierre B, Stichnoth FA, Hori A, et al. Intracerebral ganglioglioma. F Neurosurg 1986;65:177-82.

2 Drake J, Hoffmann HJ, Kobayashi J, et al. Surgical management of children with temporal lobe epilepsy and mass lesions. Neurosurgery 1987;21:792-7.

3 Garrido E, Becker LF, Hoffman HJ, et al. Gangliogliomas in children. A clinicopathological study. Childs Brain 1978;4:339-46.

4 Kalyan-Raman UP, Olivero WC. Ganglioglioma: a correlative clinicopathological and radiological study of ten surgically treated cases with follow-up. Neurosurgery 1987;20:428-33.

5 Sutton LN, Packer RJ, Rorke LB, et al. Cerebral gangliogliomas during childhood. Neurosurgery 1983;13:124-8.

6 Zülch KJ. Atlas of Gross Neurosurgical Pathology. Berlin: Springer, 1975:49-50.

7 Perkins OC. Ganglioglioma. Arch Pathol Lab Med 1926;2: 11-7.

8 Courville CB. Ganglioglioma: tumors of the central nervous system; review of the literature and report of two cases. Archives of Neurology and Psychiatry 1930;24: 439-92.

9 Henry JM, Heffner RR, Earle KM. Gangliogliomas of the CNS: a clinicopathological study of 50 cases [abstract]. f Neuropathol Exp Neurol 1978;37:626.

10 Castillo M, Davis PC, Takei Y, et al. Intracranial ganglioglioma: MR, CT, and clinical findings in 18 patients. AfR Am $\mathcal{F}$ Roentgenol 1990;154:607-12.

11 Haddad SF, Moore SA, Menezes AH, et al. Ganglioglioma: 13-years of experience. Neurosurgery 1992;31: glioma:

12 Isla A, Alvarez F, Gutierrez M, et al. Gangliogliomas: clinical study and evolution. $\mathcal{F}$ Neurosurg Sci 1991;35:193-7.
13 Johannsson JH, Rekate HL, Roessmann U. Gangliogliomas: pathological and clinical correlation. f Neurosurg 1981;54:58-63.

14 Russell DS, Rubinstein LJ. Pathology of the tumors of the nervous system.

15 Silver JM, Rawlings CE, Rossitch E, et al. Ganglioglioma: a clinical study with long term follow-up. Surg Neurol

16 Kleinhues P, Burger PC, Scheithauer BW. Histological typing of tumours of the central nervous system. World Health Organization, international histological classification of tumors. 2nd ed. New York: Springer, 1993.

17 Campos MG, Zentner J, Ostertun B, et al. Anaplastic ganglioglioma: case report and review of the literature. Neurol Res 1993;16:317-20.

18 Cushing H. Intracranial tumors. Notes upon a series of 2000 verified cases with surgical mortality percentages pertaining thereto. Springfield, Ill: Charles C Thomas, 1932:9-68.

19 Casazza M, Avanzini G, Broggi G, et al. Epilepsy course in cerebral gangliogliomas: a study of 16 cases. Acta Neurochir (suppl) 1989;46:17-20.

20 Tampieri D, Moumdjian R, Melanson D, et al. Intracerebral gangliogliomas in patients with partial complex seizures: CT and MR imaging findings. $A \mp N R$ Am $₹$ Neuroradiol 1991;12:749-55.

21 Wolf HK, Campos MG, Zentner J, et al. Surgical pathology of temporal lobe epilepsy. Experience with 216 cases. F Neuropathol Exp Neurol 1993;52:499-506.

22 Imanage $\mathrm{H}$, Kubo $\mathrm{O}$, Izawa $M$, et al. Clinical study of gangliogliomas in cerebral hemisphere. No Shinkei Geka 1984;12:627-33.

23 Pilcher WH, Silbergeld DL, Berger MS, et al. Intraoperative electrocorticography during tumor resection: impact on seizure outcome in patients with gangliogliomas. F Neurosurg 1993;78:891-902.

24 Albright L, Byrd RP. Ganglioglioma of the entire spinal cord. Childs Brain 1980;6:274-80.

25 Bevilacqua G, Sarnelli R. Ganglioglioma of the spinal cord. A case with long survival. Acta Neuropathol 1979;48:239-42.

26 Epstein N, Epstein F, Allen JC, et al. Intractable focal pain associated with a ganglioglioma of the cervicomedullary junction: report of a case. Neurosurgery 1982;10:612-6.

27 Nass R, Whelan MA. Gangliogliomas. Neuroradiology 1981;22:67-71.

28 Garcia CA, McGarry PA, Collada M. Ganglioglioma of the brain stem. Case report. F Neurosurg 1984;60:431-4.

29 Gonlim-Oliveira JA, Choux M. Tumeurs du tronc cérébral chez l'enfant. Neurobiologia 1982;45:167-80.

30 Doyle JB, Kernohan JW. Ganglioneuroma of the third ventricle with diabetes insipidus and hypopituitarism. 7 Nerv Ment Dis 1931;73:55-61.

31 Mizuno Z, Nishio S, Barrow DL, et al. Ganglioglioma of the cerebellum: case report. Neurosurgery 1987;21: 584-8.

32 Packen RJ, Sutton LN, Rosenstock JG, et al. Pineal region tumors of childhood. Pediatrics 1984;74:97-102.

33 Tokoro K, Chiba Y, Ohtani T, et al. Pineal ganglioglioma in a patient with familial basal ganglia calcification and elea patient with familial basal ganglia calcification and elevated $\operatorname{serum} \alpha$-fe

34 Chilton J, Caughron MR, Kepes JJ. Ganglioglioma of the optic chiasm: case report and review of the literature. Neurosurgery 1990;26:1042-5.

35 Gritzman MCD, Snyckers FD, Proctor NSF. Ganglioglioma of the optic nerve. A case report. $S$ Afr Med F 1983;63:863-5.

36 Dorne HL, O'Gorman AM, Melanson D. Computed tomography of intracranial gangliogliomas. AfNR $\mathrm{Am} \mathfrak{f}$ Neuroradiol 1986;7:281-5.

37 Cheung YK, Fung CF, Chan FU, et al. MRI features of spinal ganglioglioma. Clin Imaging 1991;15:109-12.

38 Fletcher WA, Hoyt WF, Narahara MH. Congenital quadrantanopia with occipital lobe ganglioglioma. Neurology 1988;38:1892-4. 